\title{
PROXIMAL FEMURAL VALGUS SUBTROCHANTERIC OSTEOTOMY FOR NON UNION OF TROCHANTERIC FRACTURES
}

Paulo Silva', Danilo Lopes Coelho², Calim Curi Júnior², Leandro Alves de Oliveira², Frederico Barra de Moraes ${ }^{3}$, Rogério Andrade do $\mathrm{Amaral}^{4}$, Percival Rosa Rebello 4

\section{ABSTRACT}

Objectives: To evaluate valgus subtrochanteric osteotomy for the treatment of trochanteric non-union. Methods: A retrospective study of cases series. From 1998 September to 2009 January, seventeen (17) cases with a diagnosis of non-union of trochanteric fracture were re-operated by the hip group of the Ortophaedic And Traumatology service of the Hospital Geral de Goiania (HGG). The patients presented pain at the fracture site, a femoral varus angle of less than $120^{\circ}$, and non-union of the fracture in the $3^{\text {rd }}$ months after the initial surgery. Results: Patients with ages ranging from 30 to 73 years, with a maximum follow-up of 09 years and minimum of 09 years. The mean time from first surgery to osteotomy was six months. Bone union was observed in 16 patients, with a mean union

\section{INTRODUCTION}

Several epidemiological studies have suggested that the incidence of transtrochanteric fractures of the femur has increased significantly over recent decades and that they are one of the biggest causes of morbidity and mortality among elderly patients. Such individuals represent an increasingly important proportion of the population because of better quality of life and consequent better aging. These fractures mostly occur in individuals over the age of 60 years, and usually among postmenopausal women in association with osteoporosis. They come from trauma of moderate or even minimal energy, but they may also be present in younger patients due to high-energy accidents ${ }^{(1-3)}$.

Skewed bone consolidation in varus and non- time of 12 weeks after surgery. The mean hip varus angle was $105^{\circ}\left(120^{\circ}\right.$ to $\left.90^{\circ}\right)$. After surgery, the mean hip valgus angle was $144^{0}\left(155^{\circ}\right.$ to $\left.135^{\circ}\right)$. We had one unsuccessful case; a 78-year old patient who had osteogtomy, fixed with DHS of $150^{\circ}$, with valgization to $154^{0}$. After six months of follow-up without union of the fracture, it was decided to perform total cemented hip artroplasthy, without complications. Conclusion: Valgus subtrochanteric osteotomies can be indicated for the treatment of trochanteric treatment of pseudoarthroses, with good final results for bone union, avoiding the need for total hip artroplasthy and maintaining biological fixation, as well as reestablishing the mechanical and anatomical axis of the affected limb.

Keywords - Hip Fractures; Pseudarthrosis; Femoral Fractures consolidation are the most frequent biomechanical complications in unstable transtrochanteric fractures. When these occur, it leads to shortening of the affected limb and changes to its mechanical axis, disequilibrium of the abductor musculature and overloading at the level of the lumbar spine and knee. Such cases may also evolve with pain and complications of greater seriousness, such as hip and knee arthrosis, over the medium or long term ${ }^{(4-7)}$.

The incidence of non-consolidation as a complication of transtrochanteric fracture is low (around 1\%), and this is due to the excellent vascularization in this region. Non-consolidation due to failure of internal synthesis material usually occurs earlier. Valgization osteotomy is a therapeutic option that is considered to be effective for treating consolidation failure of

1 - Head of the Hip Surgery Service of the Hospital Geral de Goiânia - GO, Brazil.

2 - Orthopedic Intern Doctor of the Hip Surgery Service of the Hospital Geral de Goiânia - GO, Brazil.

3 - Assistant Professor of the Department of Orthopedics, Medical Faculty, Universidade Federal de Goiás- GO, Brazil

4 - Orthopedist of the Hip Surgery Service of the Hospital Geral de Goiânia - GO, Brazil.

Work carried out at the Hip Surgery Service of the Hospital Geral de Goiânia and at the COT - Orthopedic and Traumatology Clinic of Goiânia - Goiás.

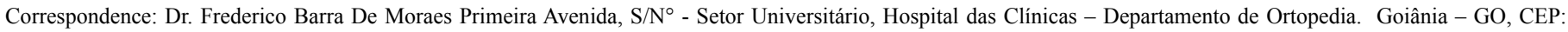
E-mail: frederico_barra@yahoo.com.br

Received for publication: 06/06/2011, accepted for publication: 07/13/2011

The authors declare that there was no conflict of interest in conducting this work 
transtrochanteric fractures. This technique reestablishes the biomechanical axis of the limb and the abductor lever arm, with redirection of the force vector and consequent consolidation of the fracture and the osteotomy. There are few studies in the literature on this topic ${ }^{(8-12)}$.

Our study had the aim of evaluating the results from subtrochanteric valgization osteotomy of the proximal femur, performed to treat unconsolidated transtrochanteric fractures in a single institution: Goiânia General Hospital (HGG).

\section{MATERIALS AND METHODS}

Between September 1998 and January 2009, 17 patients with a diagnosis of non-consolidation of a transtrochanteric fracture were reoperated by the Hip Group of the Orthopedics and Traumatology Service at HGG. These patients presented pain at the fracture site, a varus angle of the femur less than or equal to $120^{\circ}$ and continuing non-consolidation of the fracture in the third month after the first operation.

In the clinical evaluation to plan the surgery, factors such as the presence of claudication due to shortening greater than $2 \mathrm{~cm}$, rotational deviation of the affected limb, diminished range of motion and the patient's decision to undergo a new surgical procedure were taken into consideration.

Radiographic examinations were performed before and after the operation, in anteroposterior and lateral views and with maximum adduction and abduction of the compromised hip, and these did not show any evidence of hip osteoarthritis. The cervical-diaphyseal angles were measured bilaterally, with the aim of restoring the normal angle, in comparison with the unaffected side.

The access route used was anterolateral (WatsonJones), with a mean incision length of $20 \mathrm{~cm}$. In all the surgical procedures, intraoperative radioscopy was used, to guide the osteotomy and the positioning of the synthesis material.

The surgical technique used was subtrochanteric valgization osteotomy by means of resection of a lateral subtraction wedge, with lateralization of the femoral diaphysis, thereby avoiding valgus overloading of the knee, combined with internal fixation. The valgization angle used was $145^{\circ}$, and angle of the wedge to be removed corresponded to the difference between $145^{\circ}$ and the individual varization angles of the hips evaluated. The osteotomy sites and the fixation site were also planned. In cases of excessive elongation caused by valgization, a bone ring was resected from the distal fragment, taking the contralateral limb as the reference for equalization.

Antibiotic prophylaxis was administered, consisting of first-generation cephalosporin for 72 hours, along with thromboembolism prophylaxis consisting of low molecular weight heparin for two weeks, for all the patients. A suction drain was used for $48 \mathrm{~h}$ after the operation.

Subtrochanteric valgization osteotomy was performed in other cases of non-consolidation or stress fracture of the femoral neck, with good results, but these cases were not added to our work.

All the patients were operated by the same group of surgeons and with the same surgical technique, and the only variation was in relation to the synthesis material used: dynamic hip screw (DHS), dynamic condylar screw (DCS) or laminar plate. All the patients agreed with the proposed treatment, and they were given explanations about the risk of non-success and the possible need for new surgical interventions. The data were analyzed statistically in a descriptive manner.

\section{RESULTS}

All the cases were of patients who had suffered transtrochanteric fractures, had undergone operations and had evolved with pain together with non-consolidation of the fracture, varus deviation of the proximal femur and shortening of the limb affected (Table 1).

The mean length of time between the first surgical procedure and the last was seven, with a range from three to nine months. Out of the 17 cases, eight were female and nine were male, with a mean age of 57.8 years, ranging from 30 to 87 years.

Regarding the initial treatment, 13 of the 17 cases were operated by another team, and four were complications from our service. The fixation method used previously was DHS in 11 cases, laminated plate in four cases, PFN in one case and DCS in one case. Only two cases had had two previous procedures, and these were performed in another service.

The preoperative varization angle of the hip was calculated and the mean value was found to be $105^{\circ}$ of varus, with a maximum of $120^{\circ}$ and minimum of $90^{\circ}$. The postoperative valgization angle was also calculated, and its mean was $144^{\circ}$ of valgus, with a maximum of $155^{\circ}$ and a minimum of $135^{\circ}$ (Figure 1). 
Table 1 - Patient distribution according to the clinical and surgical characteristics before and after the valgization osteotomy for treating non-consolidation of transtrochanteric fractures of the proximal femur.

\begin{tabular}{|c|c|c|c|c|c|c|c|c|c|c|}
\hline Patient & Sex & Age & Fracture & First surgery & Varus & $\begin{array}{l}\text { Time elapsed } \\
\text { until second } \\
\text { surgery }\end{array}$ & $\begin{array}{l}\text { Second surgery: } \\
\text { technique }\end{array}$ & Valgus & $\begin{array}{c}\text { Time taken to } \\
\text { consolidate }\end{array}$ & Notes \\
\hline 1 & $\mathrm{~F}$ & 87 & TT & PFN & $107^{0}$ & 7 months & OSV + DHS 135 & $140^{\circ}$ & 3 months & \\
\hline 2 & M & 33 & TT & DHS 135 & $104^{0}$ & 4 months & OSV + PL 150 & $148^{\circ}$ & 4 months & \\
\hline 3 & $M$ & 78 & TT & PL 150 & $109^{\circ}$ & 3 months & OSV + DHS 150 & $154^{\circ}$ & $\mathrm{N}$ consolid. & ATQ \\
\hline 4 & M & 30 & TT & PL 150 & $100^{\circ}$ & 5 months & OSV + DHS 150 & $150^{\circ}$ & 3 months & \\
\hline 5 & $M$ & 37 & $\begin{array}{l}\mathrm{TT}+\mathrm{di}- \\
\text { aphysis }\end{array}$ & $\begin{array}{c}\text { DHS } 135+ \\
\text { diaphysis plate }\end{array}$ & $90^{\circ}$ & 5 months & OSV + PL 135 & $140^{\circ}$ & $31 / 2$ months & \\
\hline 6 & $M$ & 49 & TT & DHS 135 & $120^{\circ}$ & 4 months & OSV + PL135 & $145^{\circ}$ & 3 months & \\
\hline 7 & M & 50 & TT & DHS 135 & $98^{\circ}$ & 6 months & OSV + DHS 135 & $154^{\circ}$ & 4 months & \\
\hline 8 & M & 34 & TT & DHS 135 & $107^{0}$ & 6 months & OSV + DHS 135 & $135^{\circ}$ & 5 months & \\
\hline 9 & $\mathrm{M}$ & 68 & TT & DCS 90 (FM) & $100^{\circ}$ & 5 months & OSV + DHS 135 & $155^{\circ}$ & $41 / 2$ months & \\
\hline 10 & M & 75 & TT & $\begin{array}{c}\text { DCS } 90 \\
\text { PL } 135 \text { (FM) }\end{array}$ & $97^{\circ} 110^{\circ}$ & $\begin{array}{l}4 \text { months } \\
7 \text { months }\end{array}$ & OSV + PL 135 & $140^{\circ}$ & 4 months & $\begin{array}{l}2 \text { previous } \\
\text { operations }\end{array}$ \\
\hline 11 & $\mathrm{~F}$ & 72 & TT & $\begin{array}{l}\text { DHS } 135 \\
\text { PL } 90\end{array}$ & $\begin{array}{l}120^{\circ} \\
105^{\circ}\end{array}$ & $\begin{array}{l}5 \text { months } \\
9 \text { months }\end{array}$ & OSV + DHS 150 & $150^{\circ}$ & 4 months & $\begin{array}{l}2 \text { previous } \\
\text { operations }\end{array}$ \\
\hline 12 & $\mathrm{~F}$ & 71 & TT & DHS 135 & $105^{\circ}$ & 6 months & OSV + DHS 135 & $135^{\circ}$ & 4 months & \\
\hline 13 & $\mathrm{~F}$ & 79 & TT & DHS 135 (FM) & $100^{\circ}$ & 7 months & OSV + DCS 90 & $148^{\circ}$ & 3 months & \\
\hline 14 & $\mathrm{~F}$ & 45 & TT & DHS 135 & $115^{\circ}$ & 7 months & OSV + PL 150 & $150^{\circ}$ & 3 months & \\
\hline 15 & $\mathrm{~F}$ & 59 & TT & DHS 135 & $107^{\circ}$ & 5 months & OSV + DHS 135 & $140^{\circ}$ & 3 months & \\
\hline 16 & $\mathrm{~F}$ & 63 & TT & DHS 135 & $110^{\circ}$ & 6 months & OSV+ DHS 135 & $138^{\circ}$ & 3 months & DVT \\
\hline 17 & $\mathrm{~F}$ & 54 & TT & DHS 135 & $112^{0}$ & 5 months & OSV+ DHS 135 & $135^{\circ}$ & $21 / 2$ months & \\
\hline
\end{tabular}

Among the osteotomies, eleven were fixed using a DHS, one was fixed with a DCS and five were fixed with a laminated plate. The synthesis material was chosen in accordance with the preoperative planning (Figure 2).

The duration of the operation varied, with a mean of 90 minutes. In eight cases, postoperative blood transfusion was necessary. The mean time taken for the osteotomies and fractures to consolidate was 12 weeks, and the mean length of follow-up was five years.

We did not have any cases of infection or necrosis of the femoral head, but we had one case of thromboembolic complication (deep vein thrombosis). This was treated conservatively for 30 days, with follow-up from the angiology team, and presented good evolution.

We had one unsuccessful case: a 78-year-old patient who underwent osteotomy that was fixed with a DHS of $150^{\circ}$ and valgization to $154^{\circ}$. After six months of follow-up without fracture consolidation, it was decided to perform cemented total hip arthroplasty, which was achieved without intercurrences (Figure 3).

\section{DISCUSSION}

Valgization osteotomy of the proximal femur is a technique used for treating several pathological conditions of the hip (osteoarthritis, post-dysplasia deformities, adolescent coxa vara, avascular necrosis of the femoral head, pseudoarthrosis and skewed consolidation). It has been described by several authors, mainly in the 1970s and 1980s, but more recently, with advances in hip arthroplasty, it has been left aside. The contraindications for femoral osteotomy include: 1) presence of infection, which may prevent use of internal fixation, although external fixation may be a viable option in these cases; 2) limitations on hip movement; 3 ) osteoarthrosis or osteonecrosis is a relative contraindication; and 4) inflammatory arthritis. Few studies in the literature have discussed osteotomy as a treatment for intertrochanteric pseudarthrosis, very likely because it is considered to be a rare complication ${ }^{(5-11)}$. 


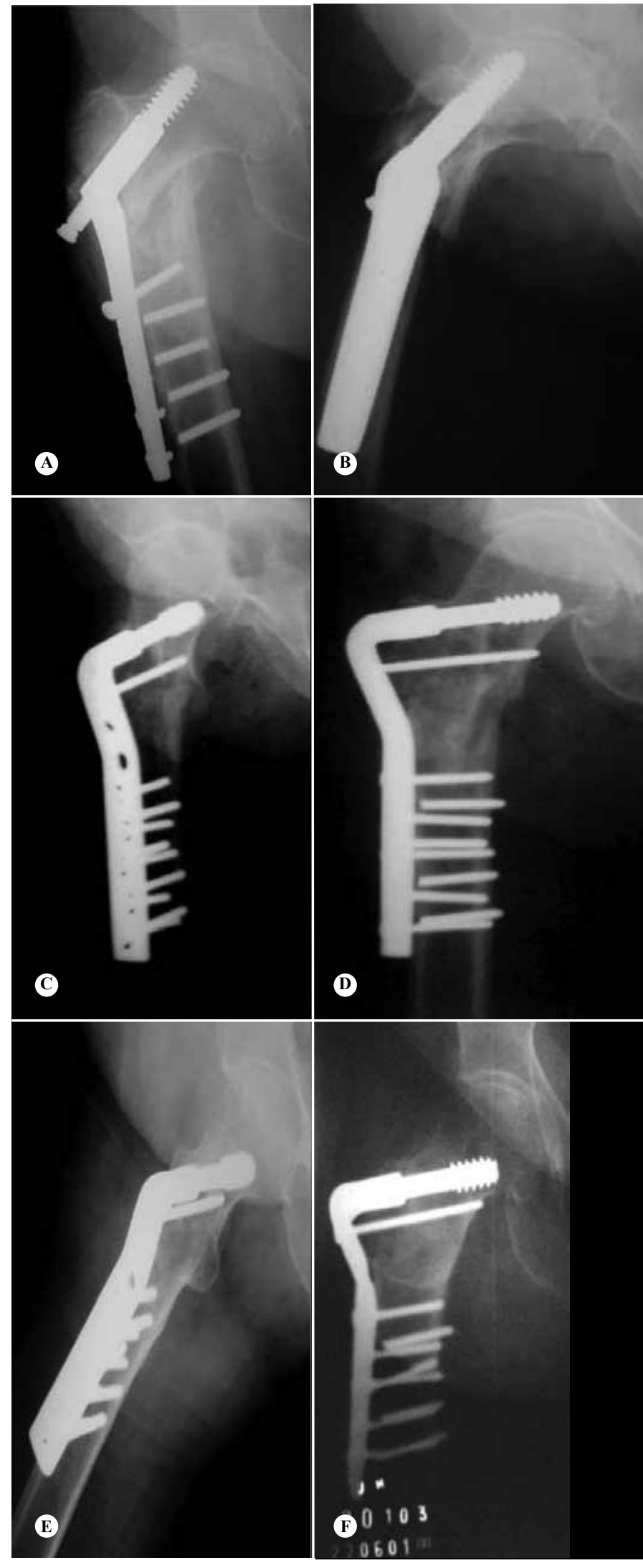

Figure 1 - 79-year-old patient who, seven months after the first surgery, evolved with transtrochanteric pseudarthrosis, with 100 degrees of varus of the proximal femur (A and $B)$. Three months after valgization osteotomy, at 148 degrees ( $C$ and $D)$, fracture consolidation was achieved ( $\mathrm{E}$ and $\mathrm{F})$.
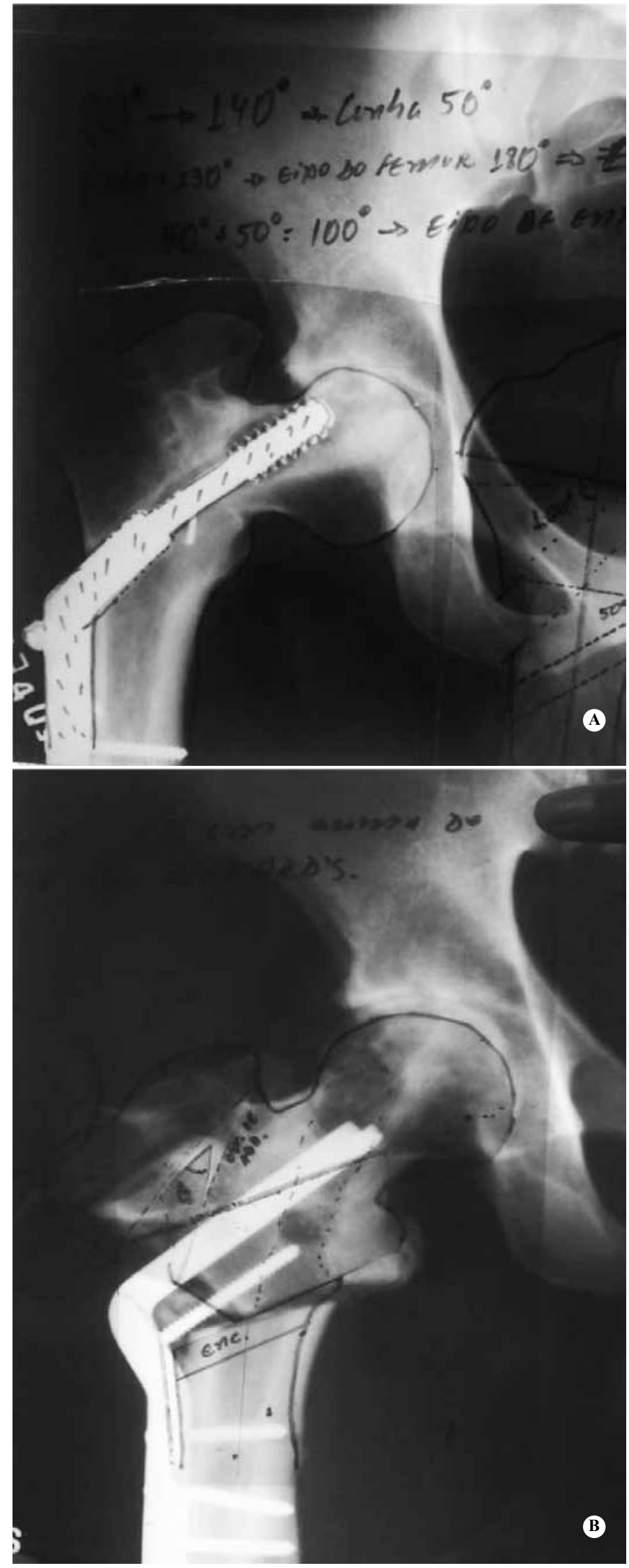

Figure 2 - Preoperative planning for valgization osteotomy of the proximal femur, to correct the varus deformity caused by transtrochanteric pseudoarthrosis (A and $B)$. 


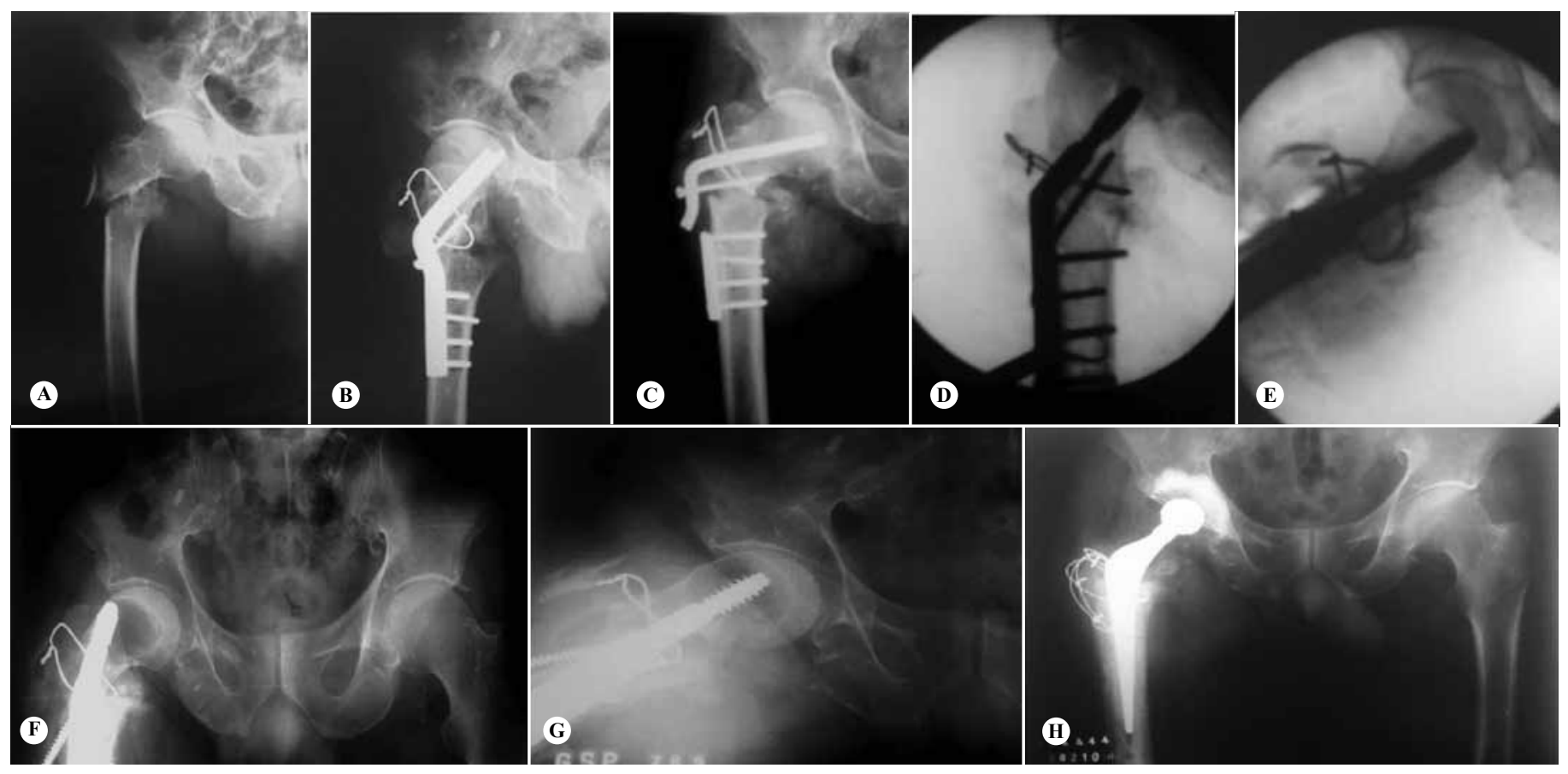

Figure 3 - 78-year-old patient with pseudarthrosis and failure of the material (A, B and C), who underwent osteotomy that was fixed with a DHS of $150^{\circ}$ and valgization to $154^{\circ}(\mathrm{D}$ and $\mathrm{E})$. After six months of follow-up without fracture consolidation or "cut out" of the material $(F$ and $G)$, it was decided to perform cemented total hip arthroplasty, which was achieved without intercurrences $(H)$.

Fractures of the proximal femur are subjected to intense mechanical forces in small segments of bone, which reach $1250 \mathrm{lb} / \mathrm{cm}^{2}$ of compression on the medial side and $1000 \mathrm{lb} / \mathrm{cm}^{2}$ of tension on the lateral side, for every $100 \mathrm{lb}^{(13)}$, thus requiring implants with trustworthy fixation. Consolidation of these fractures will depend especially on anatomical reduction and maintenance of the irrigation of the proximal femur, through the medial branch of the femoral circumflex artery. Other relevant anatomical data include the normal cervical-diaphyseal angle (between 124 and $136^{\circ}$ ) and the line that joins the center of the femoral head to the tip of the greater trochanter, which forms an angle of $90^{\circ}$ (variation from $\left.85-95^{\circ}\right)$ with the mechanical axis of the femur ${ }^{(12-14)}$.

The osteotomy site may vary according to the technique. In our study, subtrochanteric valgization osteotomy was performed on all the patients, but several authors have recommended valgus intertrochanteric osteotomy (VITO), with good results. Marti et $\mathrm{al}^{(10)}$ described a series of cases of nonunion (24 patients), in which only one case was consolidation not achieved (because of infection), and Said et $\mathrm{al}^{(5)}$ reported on 18 patients with VITO, using a 130-degree plate, among whom consolidation was achieved in all cases, after a mean of 17 weeks.

The valgization angle provided by wedge resection does not contribute much towards elongating the limb.
However, the thickness of the wedge influences this elongation. With the same wedge angle, the smaller the wedge thickness is, the greater the elongation is. In addition, lateralization of the femoral diaphysis also provides an increase in the length of the affected limb. However, the smaller the wedge thickness is and the greater the lateralization of the diaphysis is, the greater the chance is that the osteotomy will not consolidate, thereby leading to new pseudarthrosis.

A wedge of 30 degrees with two thirds of the femoral diameter is sufficient to correct most defects. If a correction greater than 40 degrees is needed, it is better to use a wedge with only half of the diameter of the femoral diaphysis. Medial release of the soft tissues, such as the joint capsule and the iliopsoas tendon at the lesser trochanter facilitate diaphyseal lateralization and reduction of the osteotomy fragments. However, this release should be done carefully so as not to harm the irrigation of the femoral head.

The surgical technique used in our study was subtrochanteric valgization osteotomy by means of resection of a lateral subtraction wedge, with lateralization of the femoral diaphysis, thereby avoiding valgus overloading of the knee, combined with internal fixation. The valgization angle used was $145^{\circ}$, and angle of the wedge to be removed corresponded to the difference between $145^{\circ}$ and the individual varization 
angles of the hips evaluated. The osteotomy sites and the fixation site were also planned.

One surgical step that differed in some patients in this study consisted of resection of a ring from the femoral diaphysis, in order to avoid pressure on the femoral head and consequent osteonecrosis. This surgical step was done in cases of excessing elongation caused by valgization, taking the contralateral limb as the reference for equalization.

We observed two cases of complications: one consisting of deep vein thrombosis, which was treated clinically and was resolved; and the other was a case of non-consolidation of osteotomy in a 78-year-old patient who underwent osteotomy, which was fixed with a DHS of $150^{\circ}$, with valgization to $154^{\circ}$. In the latter case, after six months of follow-up without frac- ture consolidation, it was decided to carry out cemented total hip arthroplasty, which was free from intercurrences. However, it has to be remembered that arthroplasty has complications inherent to the procedure, which may make other surgical corrections impossible. Hence, arthroplasty should only be done as the last option.

\section{CONCLUSION}

Subtrochanteric valgization osteotomy can be indicated for treating pseudarthrosis in cases of transtrochanteric fractures, with good final consolidation results, thus avoiding replacement of the prosthesis and maintaining a biological fixation, as well as reestablishing the mechanical and anatomical axis of the affected limb.

\section{REFERENCES}

1. Russel TA. União defeituosa das fraturas - quadril e pelve. In: Crenshaw AH. Cirurgia ortopedica de Campbell. Tradução de SCAG Nascimento. 8a. ed. Rio de Janeiro : Manole; 1996. p. 955-1056.

2. Rocha MA, Carvalho WS, Zanqueta C, Lemos SC. Estudo epidemiológico retrospectivo das fraturas do fêmur proximal tratados no Hospital Escola da Faculdade de Medicina do Triângulo Mineiro. Rev Bras.Ortop. 2001;36(8):311-6.

3. Kenzora JE, McCarthy RE, Lowell JD, Sledge CB. Hip fracture mortality. Relation to age, treatment, preoperative illness, time of surgery, and complications. Clin Orthop Relat Res. 1984;(186):45-56.

4. Adams $\mathrm{Cl}$, Robinson CM, Court-Brown CM, McQueen MM. Prospective randomized controlled trial of an intramedullary nail versus dynamic screw and plate for intertrochanteric fractures of the femur. J Orthop Trauma. 2001;15(6):394-400.

5. Said GZ, Farouk O, El-Sayed A, Said HG. Salvage of failed dynamic hip screw fixation of intertrochanteric fractures. Injury. 2006;37(2):194-202

6. Bartonícek J, Skála-Rosenbaum J, Dousa P. Valgus intertrochanteric osteotomy for malunion and nonunion of trochanteric fractures. J Orthop Trauma. 2003;17(9):606-12

7. Paul RT, Kuzyk MA, Waddell JP, Mckee MD, Schemitschi EH. Surgical tech- niques for the management of proximal femoral fracture non-unions. Op Techn Ortop. 2008;18(2):114-20.

8. Mariani EM, Rand JA. Nonunion of intertrochanteric fractures of the fêmur following open reduction and internal fixation. Results of second attempts to gain union. Clin Orthop Relat Res. 1987;(218):81-9.

9. Ballmer FT, Ballmer PM, Mast JW, Ganz R. [Results of repositioning osteotomies in delayed healing or pseudarthrosis of the proximal femur]. Unfallchirurg. 1992;95(10):511-7.

10. Marti RK, Raaymakers EL, Nolte P, Besselaar PP. Pseudarthrosen am proximalen femur. Orthopade. 1996;25(5):454-62.

11. Vidyadhara S, Rao SK, Pandian S, Gnanadoss J. Closing lateral wedge valgus osteotomy with dynamic hip screw for the treatment of varus nonunion of pertrochanteric fracture: can restoration of biomechanics and stabilization alone heal? Arch Orthop Trauma Surg. 2009;129(6):827-32. 6.

12. Pauwels F. Biomechanics of the normal and diseased hip. Berlin: Springer; 1976.

13. Koch JC. The laws of bone architecture. Am J Anat. 1917;21:177-298.

14. Schatzker J. The Intertrochanteric Osteotomy. Berlin: Springer; 1984. 